\title{
Structural equation modeling of psychopathic traits in Chilean female offenders using the Self-Report Psychopathy-Short Form (SRP-SF) Scale: a comparison of gender-based item modifications versus standard items
}

\author{
Elizabeth León-Mayer, ${ }^{1}$ (iD Joanna Rocuant-Salinas, ${ }^{1}$ Hedwig Eisenbarth, ${ }^{2}$ Jorge Folino, ${ }^{1}$ \\ Craig Neumann ${ }^{3}$ iD \\ ${ }^{1}$ Universidad Nacional de La Plata, La Plata, Argentina. ${ }^{2}$ University of North Texas, Denton, TX, USA. ${ }^{3}$ University of Southampton, \\ Southampton, UK. iD EL-M https://orcid.org/0000-0003-1564-6448, iD CN https://orcid.org/0000-0002-3825-2153
}

\begin{abstract}
Objective: To examine the utility of the Self-Report Psychopathy-Short Form (SRP-SF) to assess psychopathic traits in female offenders and to test gender-based item modifications.

Method: A South American sample of female offenders $(n=210)$ was assessed with the Psychopathy Checklist-Revised (PCL-R); 110 subjects also completed the standard SRP-SF, while 109 completed a version with items rewritten to be more relevant for females. The underlying latent structure of the PCL-R and both versions of the SRP-SF were examined.

Results: Most of the modified items showed higher average item responses. The PCL-R showed a stronger association with the modified SRP-SF than with the standard SRP-SF. The four-factor model showed very good fit in accounting for the PCL-R data, consistent with previous research. For both SRP-SF versions, the results indicated good model fit. Structural equation models were tested separately, in which a superordinate SRP-SF factor was set to predict a broad factor reflecting chronic misconduct. Both versions showed good model fit, and the SRP-SF superordinate factor significantly predicted a chronic misconduct factor.

Conclusions: Both versions of the SRP-SF adequately reflected psychopathic features in this female sample; the modified items added robustness to representation of these features.
\end{abstract}

Keywords: Psychopathy; female offenders; PCL-R; self-report psychopathy scale

\section{Introduction}

The relevance of the construct of psychopathy calls for greater efforts to improve its evaluation, to discover its correlates and particularities based on gender. Among those efforts, we can highlight the development and validation of self-report instruments for the measurement of psychopathic traits. This is a scientific trend that, despite several years of international tradition, ${ }^{1,2}$ has only recently begun to develop in South America. ${ }^{3,4}$

The self-reporting approach for the evaluation of psychopathy has been questioned mainly due to its dependence on truthful information and risk of impression management by psychopathic individuals. Nevertheless, its usefulness has also been demonstrated in different circumstances and with different instruments. ${ }^{5,6}$ The advances of selfreport assessment in psychopathy have been reported by Neumann \& Pardini, ${ }^{7}$ and modeled to either assess normal

Correspondence: Elizabeth León-Mayer, Cátedra de Psiquiatría, Facultad de Ciencias Médicas, 60 y 120, CP 1900, La Plata, Argentina. E-mail: elyleonmayer@gmail.com

Submitted Oct 26 2017, accepted Mar 26 2018, Epub Oct 112018. range personality variants or traits based on the Psychopathy Checklist-Revised (PCL-R).

In addition to developments in the diagnosis of psychopathy with self-report instruments, the scientific community has also sought to increase understanding of psychopathy in women. Research with male samples continues to be predominant, but there is already specific information on psychopathy in women with regards to its prevalence; comorbidity with other disorders; risk of recidivism; assessment tools; influence of cultural effects; and differences in the manifestation of antisocial behavior, among other aspects. $^{8-11}$ While most of this information comes from North America and Europe, psychopathy research with women in South America is emerging.

Integration of the two aforementioned areas of research knowledge of psychopathy in women and self-report assessment of psychopathy - is an unexplored field in South America. Inquiry at the intersection of these two areas can

How to cite this article: León-Mayer E, Rocuant-Salinas J, Eisenbarth $\mathrm{H}$, Folino J, Neumann C. Structural equation modeling of psychopathic traits in Chilean female offenders using the Self-Report PsychopathyShort Form (SRP-SF) Scale: a comparison of gender-based item modifications versus standard items. Braz J Psychiatry. 2019;41: 31-37. http://dx.doi.org/10.1590/1516-4446-2018-0106 
help address many questions regarding the peculiarities of manifestation of psychopathy in convicted women in the region, and the usefulness of the self-report instruments to evaluate it. It may also help elucidate if information thus obtained corresponds with the PCL-based model, especially when taking into account the higher scores on psychopathy measures observed in males ${ }^{12}$ and that the symptoms of psychopathy may not factor together in women in the same way as they do in men. ${ }^{13}$

This study seeks to contribute to the search for answers to the questions posed above. We specifically propose to add evidence on the utility of a self-report instrument for measuring psychopathy in Latin American female offenders and the integrity of its underlying factor structure, as well as to test a gender-based modification of items contained in the Self-Report Psychopathy Short Form (SRP-SF). ${ }^{14}$

\section{The Self-Report Psychopathy Short Form (SRP-SF)}

The SRP-SF ${ }^{14}$ is a 29 -item scale designed to measure psychopathic features. It psychopathic traits organized in to four facets - interpersonal, affective, lifestyle, and antisocial - consistent with research on the PCL-R. ${ }^{15}$ Items are scored on a five-point Likert scale (from $1=$ strongly disagree to $5=$ strongly agree) .

The SRP and SRP-SF both have been shown to have a clear latent structure and good construct validity, ${ }^{16,17}$ and to be strongly and positively correlated with the PCL- ${ }^{1}$ and the Youth Psychopathic Traits Inventory. ${ }^{7}$ Across a wide range of diverse samples, the SRP traits are associated in the expected theoretical directions with relevant external correlates, such as criminal offenses and externalizing psychopathology, ${ }^{18}$ moral reasoning, ${ }^{19}$ amygdala activation to fearful faces ${ }^{20}$ or emotional cues, ${ }^{21}$ and lower amygdala volume. ${ }^{22}$

The Spanish version of the SRP-SF was initially used in a sample of 208 male offenders housed at the Centro de Cumplimiento Penal, a detention center in the Province of Los Andes, Chile. ${ }^{3}$ The findings were as follows: SRP-SF total score distribution was normal, with a mean of 61.6; the Cronbach's alpha coefficient for the total was 0.8 , and $0.7,0.4,0.7$ and 0.5 for the 1st, 2nd, 3rd, and 4th factors respectively; and the manifest variable correlation with PCL-R was $0.4(p=0.01)$. A latent confirmatory factor analysis was carried out, and model fit to the empirical four-factor model of psychopathy was good (incremental fit $=0.94$, absolute fit $=0.04)^{4}$

\section{Methods}

The current sample was composed of female offenders $(n=210)$ housed in the Centro Penitenciario Femenino de Santiago de Chile (CPF), a penitentiary which houses a large proportion of the country's female convicts. The sample was randomized, and constituted $36.8 \%$ of the total CPF population as of June 2014. Mean age was 32 years $(S D=10$ years; range $=19-77$ years $)$. Data for all study variables were complete for all offenders.

All offenders were assessed with the PCL-R, ${ }^{15}$ which is scored on a three-point scale $(0=$ not present;
$1=$ somewhat present; 2 = trait present). Approximately half of the sample $(n=110)$ also completed a Spanish version ${ }^{23}$ of the standard SRP-SF, ${ }^{14}$ while a similar number of cases $(n=109)$ completed a modified form of the SRPSF with several items that were rewritten to be more relevant for females with psychopathic traits. Also, 10 cases completed both the standard and modified SRP-SF. The specific items that were modified were, 2, 6, 8, 12, 16, 18, 20 , and 29. As noted above, the SRP items were scored on a scale of 1 to 5 ( 1 = strongly disagree, $5=$ strongly agree).

The underlying latent structure of the PCL-R and both forms of the SRP-SF were examined. Mplus was used for all model analyses, using standard robust weighted least squares (weighted least squares with mean and variance adjustment, WLSMV), given the ordinal nature of the item-level data. ${ }^{1}$ The comparative fit index (CFI) and root mean square error of approximation (RMSEA) were used to evaluate incremental and absolute fit, respectively.

The study had the authorization of the Metropolitan Regional Director of Gendarmería de Chile, respected the ethical principles of research in vulnerable populations, ${ }^{24}$ and was approved by the ethics committee of Universidad de Valparaíso. Informed consent was obtained from each interviewee.

\section{Results}

The mean of the PCL-R total score was $19.3(\mathrm{SD}=7.6)$, with means for the interpersonal factor $3.3(S D=2)$, Affective Factor $4.5(\mathrm{SD}=1.9)$, behavioral lifestyle factor $5.6(S D=2.3)$ and the Antisocial Factor $4.4(S D=2.9)$. The average of the summed total and scale scores for the standard SRP-SF were $54.72(\mathrm{SD}=16.88) ; 11.34(\mathrm{SD}=$ $5.25) ; 13.59(\mathrm{SD}=4.5) ; 13.47(\mathrm{SD}=5.33) ; 16.33(\mathrm{SD}=$ 5.72 ), for the total and the Interpersonal, Affective; Behavioral Lifestyle and Antisocial scales, respectively. The means for the modified SRP-SF were $54.68(\mathrm{SD}=16.95) ; 11.38$ $(\mathrm{SD}=5.26) ; 13.50(\mathrm{SD}=4.43) ; 13.44(\mathrm{SD}=5.34) ; 16.37$ $(S D=5.74)$ for the total and the Interpersonal, Affective; Behavioral Style and Antisocial scales, respectively.

For ease of interpretation, in Figure 1 below, mean item responses are displayed (i.e., average response choice by item) for both the standard and modified SRP-SF subsamples. In this way, readers can immediately know the average item endorsement (i.e., strongly disagree strongly agree) for each item. All of the modified items, except 6 and 8, showed higher average item responses, which suggested that the modified items were endorsed in the direction of higher psychopathic features.

The SRP-SF has been shown to be significantly associated with the PCL-R. ${ }^{1}$ As expected, for the present sample, these measures were significantly correlated at the manifest variable level, though the PCL-R showed a stronger association with the modified SRP-SF $(r=0.69, p<$ 0.001 ), compared to this same association with the standard SRP-SF $(r=0.39, p<0.001)$. Also, for the 10 cases that completed both the standard and modified SRP-SF measures, a Pearson correlation of $r=0.74(p<0.001)$ was found (nonparametric Spearman's rho $=0.54, p<$ 0.054 ), providing evidence of concurrent validity (note that 
SRP mean item responses - female offenders

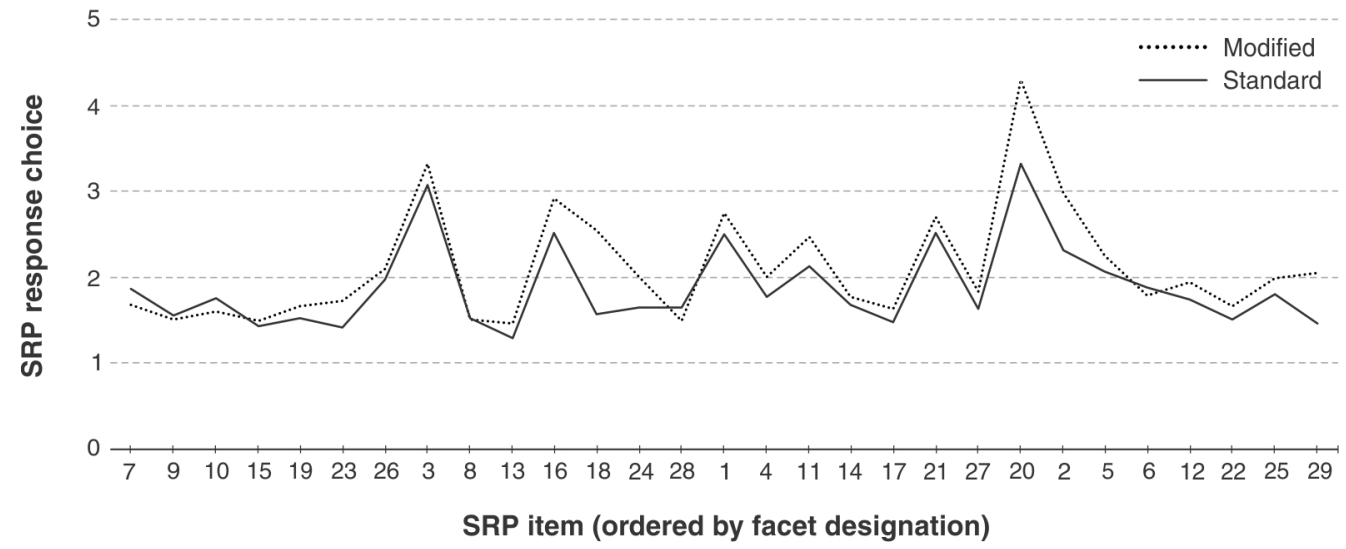

Figure 1 Standard and modified Self-Report Psychopathy-Short Form (SRP-SF), mean item responses.

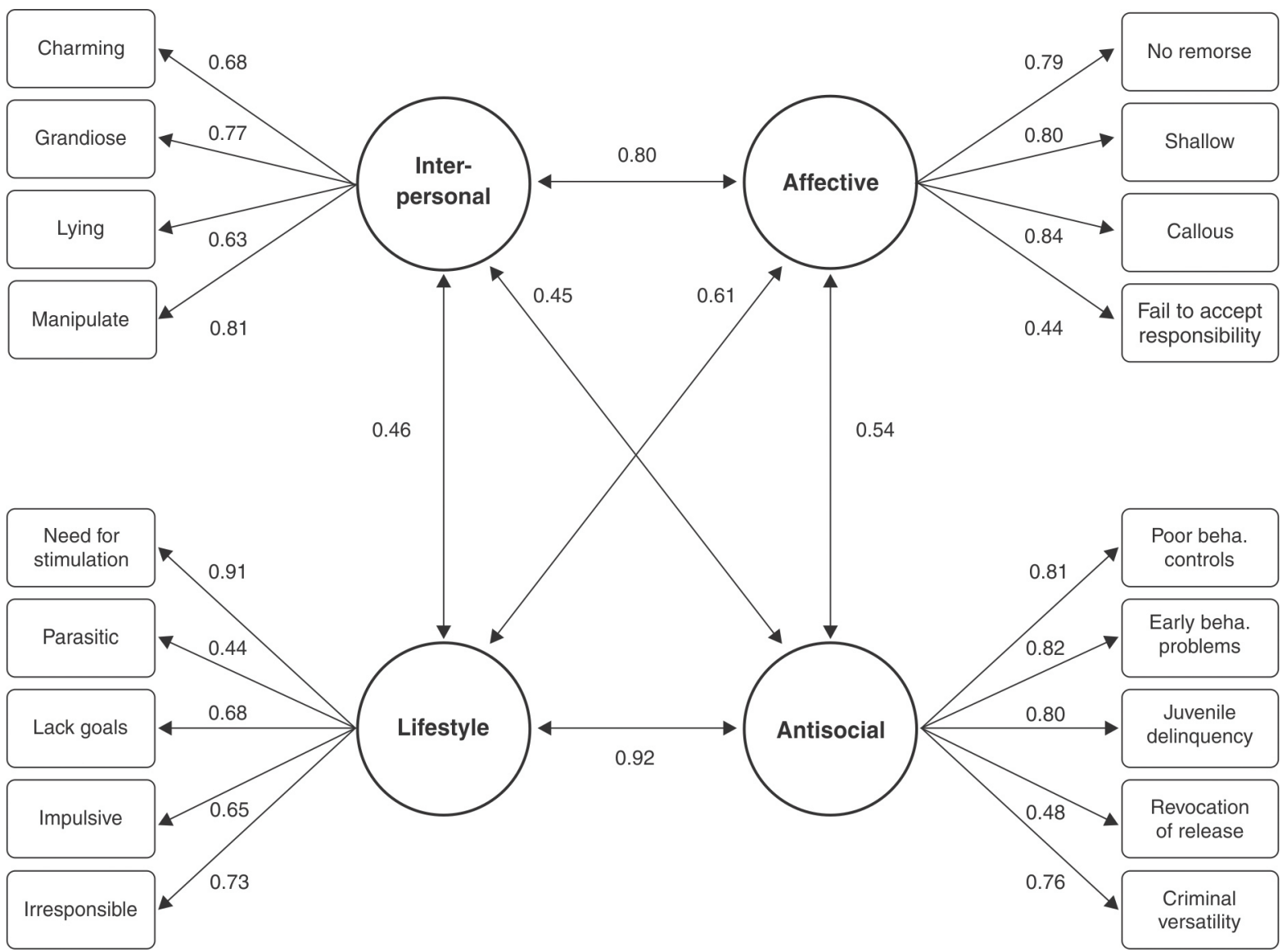

Figure 2 Standardized parameters for the four-factor Psychopathy Checklist-Revised (PCL-R) model.

corresponding SRP scale correlations provided evidence of convergent validity, $r$ range 0.66 [Interpersonal scales] to 0.84 [Antisocial scales]).

Next, the underlying latent structure of the PCL-R and both forms of the SRP-SF were examined. Previous research has demonstrated that a four-factor model can be used to account for both the PCL-R and SRP-SF items, ${ }^{1}$ which provides a viable representation of psychopathic personality. ${ }^{25}$ Consistent with previous research, the items were set to load on their respective psychopathy factors and the factors were allowed to freely correlate. With respect to the total sample, the four-factor model showed very good fit in accounting for the PCL-R data $(C F I=0.97$, RMSEA $=0.04)$. Figure 2 below displays the standardized parameters (factor loadings and correlations). All factor loadings were generally strong and significant 


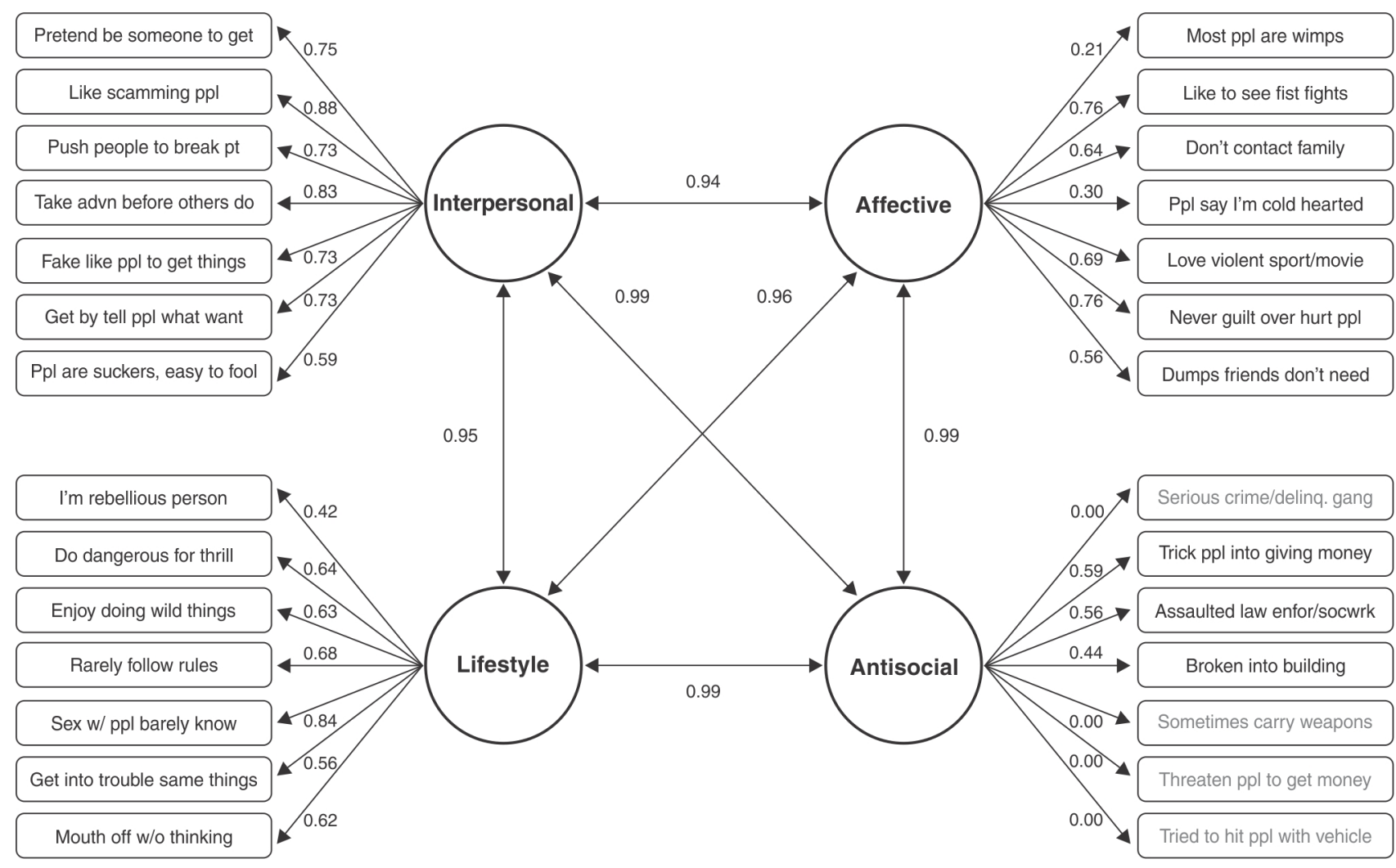

Figure 3 Standardized parameters for the four factor Self-Report Psychopathy-Short Form (SRP-SF) model (standard version).

( $p<0.01-0.001$ ), indicating that they were able to discriminate non-psychopathic from psychopathic individuals. However, three items $(9,16$, and 19) showed relatively weaker loadings, suggesting they were less effective in discriminating psychopathic from non-psychopathic females. Specifically, the items tapping parasitic orientation (item 9), failing to accept responsibility (item 16), and revocation of conditional release (item 19) may represent domains where female offenders are rated at threshold for reasons other than psychopathic personality. Finally, the four factors were strongly correlated, indicating that, together, they serve as indicators for the superordinate syndrome of psychopathic personality. ${ }^{26}$

For the SRP-SF, each version (standard and modified) was modeled separately to determine how well the fourfactor model applied in representing self-reported psychopathic traits. For the standard SRP-SF, the results indicated good model fit (CFI $=0.92$, RMSEA $=0.05)$, suggesting that it was able to adequately reflect psychopathic features in this sample of South American women. While most items loaded strongly and significantly on their respective factors, some items showed suboptimal factor loadings (items $3=$ Most people are wimps; $16=$ People sometime say I am cold-hearted), or could not be modeled due to limited variance $(20=$ I was convicted of a serious crime; 22 = Every now and then I carry a weapon [knife or gun] for protection; $25=$ I have threatened people into giving me money, clothes, or makeup; $29=1$ have purposely tried to hit someone with the vehicle I was driving). Figure 3 below displays the standardized model parameters.
For the modified SRP-SF, the results again revealed adequate fit $(\mathrm{CFI}=0.92$, RMSEA $=0.06)$, even though in this subsample, several items were modified from their original form (Figure 4). Notably, there were fewer problems with limited variance for these SRP-SF items, and all but item 20 could be included in the model. Thus, it appears the modified items added robustness to the assessment of psychopathic traits in this sample of women.

For both versions of the SRP-SF, the factors were strongly correlated, as with the PCL-R factors. Thus, there is empirical support to suggest that the four SRP-SF factors also serve as indicators for a superordinate psychopathy factor - i.e., the syndrome of psychopathic personality.

For the final set of analyses, a structural equation model (SEM) was tested in which a superordinate SRP-SF factor was set to predict a broad factor reflecting chronic misconduct. Two SEMs were tested separately for each version of the SRP. With respect to the standard SRP-SF, the SEM showed very good model fit $(\mathrm{CFI}=0.94$, RMSEA = 0.08 ) and the SRP-SF superordinate factor significantly predicted the chronic misconduct factor $(\beta=0.50)$. For the modified SRP-SF, the SEM also showed good fit (CFI = 0.96 , RMSEA $=0.06$ ), and the SRP-SF superordinate factor significantly predicted the chronic misconduct factor to a larger extent than in the previous SEM $(\beta=0.72)$. Thus, it appears that the modified SRP-SF was able to predict chronic misconduct to a greater extent than the standard SRP-SF, providing additional support for the modified items to represent psychopathic features in females. Figures 5 and 6 provide graphic representations of the two SEMs. 


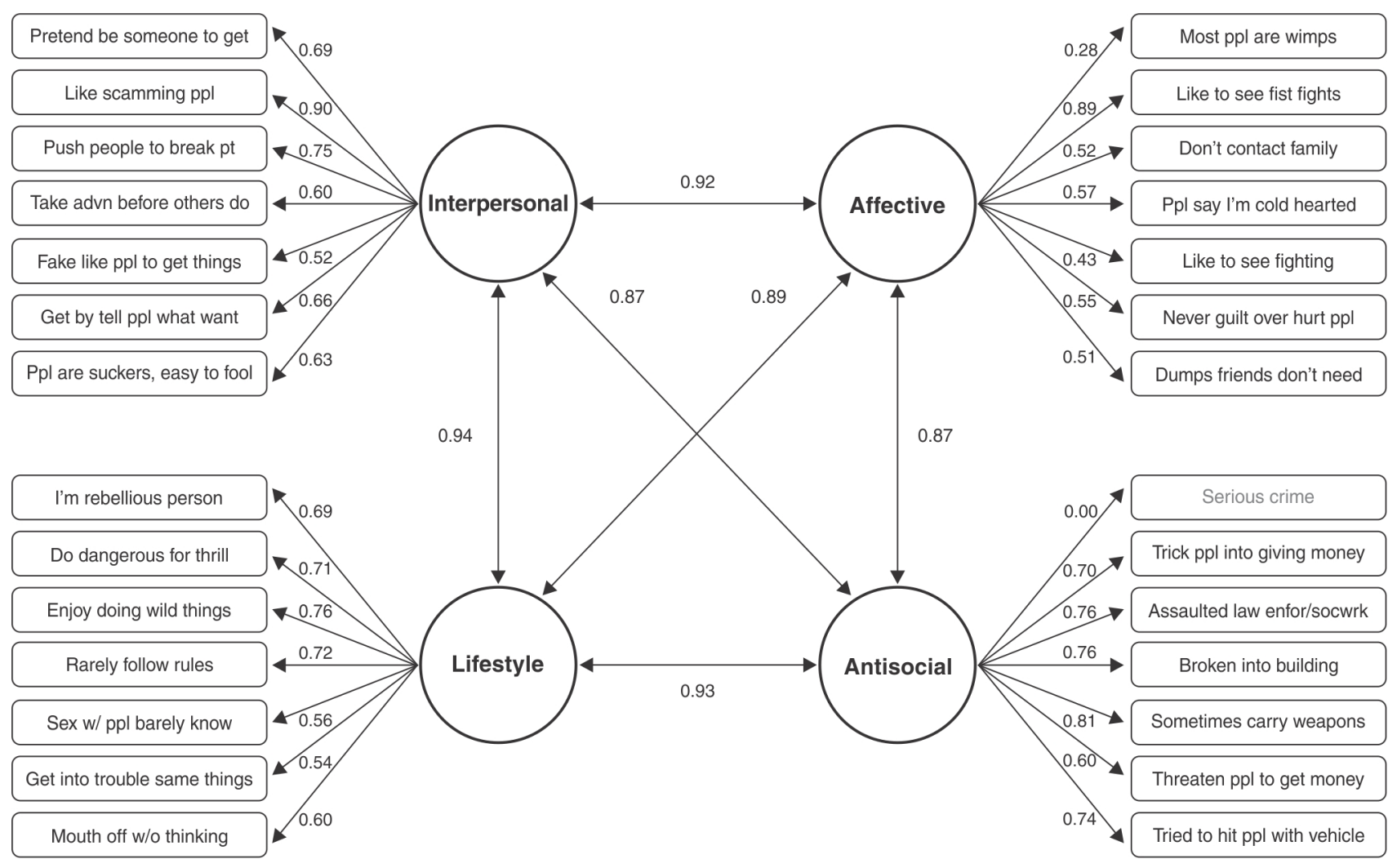

Figure 4 Standardized parameters for the four factor Self-Report Psychopathy-Short Form (SRP-SF) model (modified version).

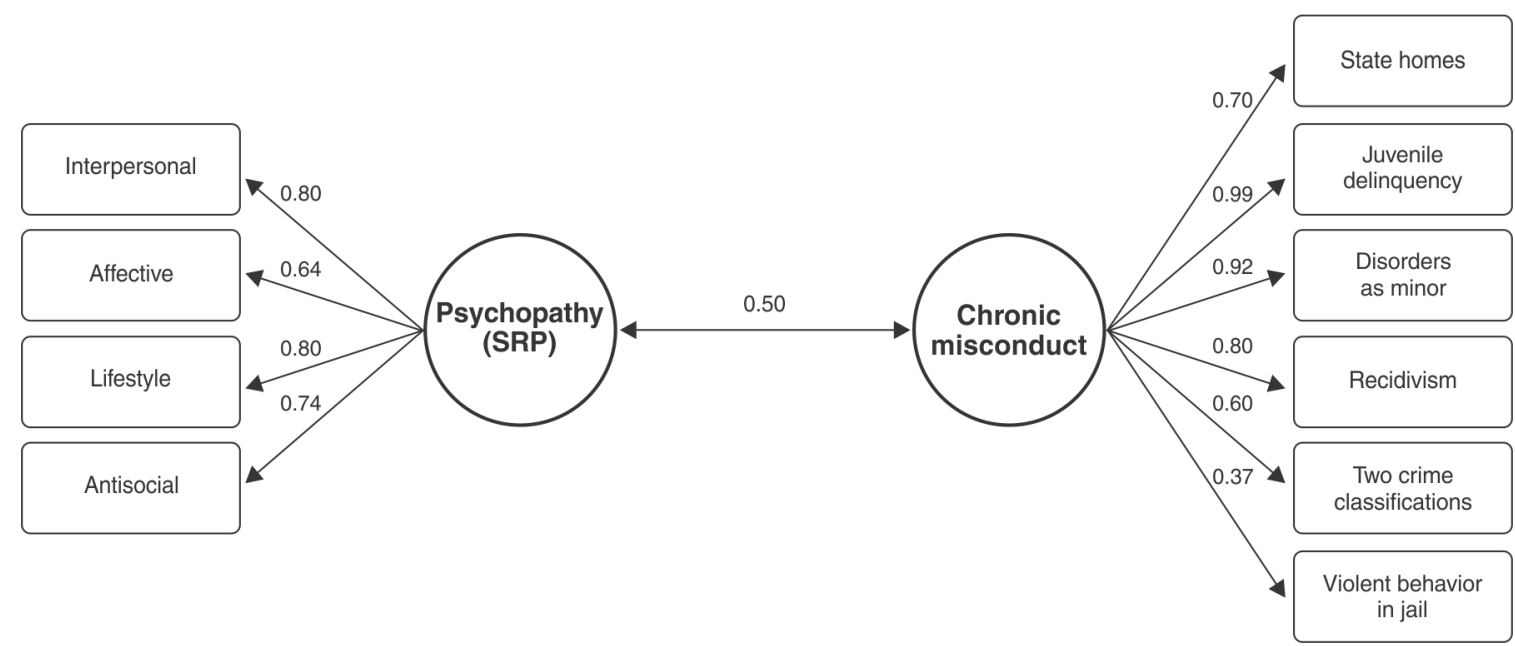

Figure 5 Structural equation model for standard Self-Report Psychopathy-Short Form (SRP-SF) and chronic misconduct.

\section{Discussion}

This study sought to obtain evidence of the utility of selfreport instruments in assessing psychopathic traits in a Latin American sample of female offenders, and to test a gender-based modified version of the SRP-F. As in previous research with convicted males in Latin America, ${ }^{3}$ our findings support the construct validity of the fourfactor model of the PCL-R. ${ }^{1}$ With respect to the total sample, this model showed very good fit with the PCL-R data $(\mathrm{CFI}=0.97$; RMSEA $=0.04)$, consistent with previous research.

Results suggest that the SRP-SF and its gender-based modified version could be used to assess psychopathic features in this South American female population. Based on higher item response rates, it appears the modified items added robustness to the assessment of psychopathic features in the sample. Moreover, the modified SRP-SF was able to predict chronic misconduct to a greater extent than the standard SRP-SF, providing 


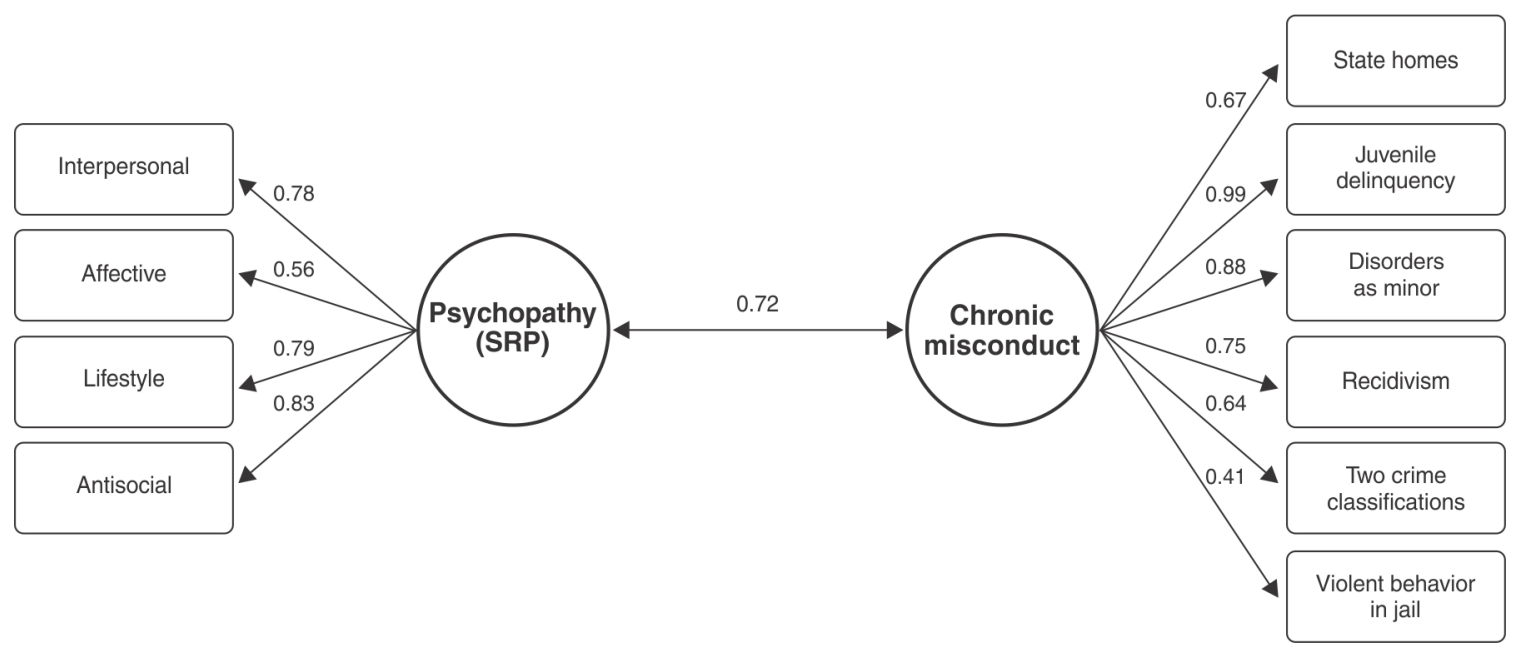

Figure 6 Structural equation model for modified Self-Report Psychopathy-Short Form (SRP-SF) and chronic misconduct.

additional support for the modified items to represent psychopathic features in females.

Self-report questionnaires might be considered of limited use in the assessment of psychopathy, given that such reports may be influenced by social desirability. The findings of the present study show that information collected with the SRP-SF is diagnostically valuable, given its significant correlation with the PCL-R. In a previous South American study, the results obtained with this instrument were also very promising. ${ }^{3}$ The present findings contribute to and extend this previous research by providing evidence for a modification of the SRP-SF items in terms of how psychopathic traits are expressed in females. At the same time, caution is warranted in the interpretation of the results, given the sample size of female offenders was somewhat small for conducting SEM. In addition, the indicators used for the chronic misconduct factor reflect the range of external correlates that were available in the current study, and the relatively smaller subsamples used for our SEMs may have influenced the precision of loadings on this factor. Nevertheless, our modeling results for the PCL-R and SRP are consistent with previous largesample research supporting their validity. ${ }^{1}$ Likewise, the SEM results are in line with other research that has examined a related set of external correlates. ${ }^{7}$

The Latin American studies with the SRP-SF conducted thus far have been based on samples of convicts, both male and female. As such, there remains an important avenue for future research with non-convicted (general population) samples. In this context, the use of a selfreport instrument, such as the SRP-SF, may facilitate data collection in community samples, because it would not require intensive assessment efforts as is required for a diagnostic tool such as the PCL-R. By no means are we advocating that the PCL-R can be replaced, given its central role in forensic assessment; however, when information on psychopathic traits in large community samples is required, priority should be given to an assessment tool - such as the SRP-SF - that is reliable and valid, is less time-consuming, and requires less professional qualifications to administer. Finally, it is important to highlight that the first development of this type of research to compare convicted vs. non-convicted populations took place recently in the Province of Salta, Argentina. ${ }^{27}$ Thus, an interesting line of research is growing in Latin American countries.

\section{Disclosure}

$\mathrm{CN}$ receives royalties from the sale of the SRP Manual. The other authors report no conflicts of interest.

\section{References}

1 Neumann CS, Hare RD, Pardini DA. Antisociality and the construct of psychopathy: data from across the globe. J Pers. 2015;83:678-92.

2 Hare R, Harpur T, Hemphill JF. Scoring pamphlet for the self report psychopathy scale: SRP-II.Vancouver: Simon Fraser University; 1989.

3 León-Mayer E, Neuman CS, Hare RR, Folino JO. Aproximación diagnóstica de psicopatía mediante instrumento autoinformado. Rev Crim. 2013;55:251-64.

4 León-Mayer E, Folino JO, Neuman C, Hare RD. The construct of psychopathy in a Chilean prison population. Rev Bras Psiquiatr. 2015;37:191-6.

5 Malterer MB, Lilienfeld SO, Neumann CS, Newman JP. Concurrent validity of the psychopathic personality inventory with offender and community samples. Assessment. 2010;17:3-15.

6 Folino JO, Mendicoa G. La Psicopatía, el MMPI y la Hare PCL R. Alcmeon, Rev Argent Clin Neuropsiquiatrica. 2006;13:43-54.

7 Neumann CS, Pardini D. Factor structure and construct validity of the Self-Report Psychopathy (SRP) scale and the Youth Psychopathic Traits Inventory (YPI) in young men. J Pers Disord. 2014;28:419-33.

8 Nicholls TL, Ogloff JR, Brink J, Spidel A. Psychopathy in women: a review of its clinical usefulness for assessing risk for aggression and criminality. Behav Sci Law. 2005;23:779-802.

9 Salekin RT, Rogers R, Ustad KL, Sewell KW. Psychopathy and recidivism among female inmates. Law Hum Behav. 1998;22:109-28.

10 Berardino SD, Meloy JR, Sherman M, Jacobs D. Validation of the psychopathic personality inventory on a female inmate sample. Behav Sci Law. 2005;23:819-36.

11 Neumann CS, Schmitt DS, Carter R, Embley I, Hare RD. Psychopathic traits in females and males across the globe. Behav Sci Law. 2012;30:557-74.

12 Rogstad JE, Rogers R. Gender differences in contributions of emotion to psychopathy and antisocial personality disorder. Clin Psychol Rev. 2008;28:1472-84.

13 Salekin RT, Rogers R, Sewell KW. Construct validity of psychopathy in a female offender sample: a multitrait-multimethod evaluation. J Abnorm Psychol. 1997;106:576-85. 
14 Paulhus DL, Neumann CS, Hare RD. Manual for the self-reported psychopathy scale. 4th ed. Toronto: Multi-Health Systems; 2016.

15 Hare RD. The hare psychopathy checklist - revised manual. 2nd ed. Toronto: Multi-Health Systems Inc; 2003.

16 Vitacco MJ, Neumann CS, Pardini DA. Predicting future criminal offending in a community-based sample of males using self-reported psychopathy. Crim Justice Behav. 2014;41:345-63.

17 Williams KM, Paulhus DL, Hare RD. Capturing the four-factor structure of psychopathy in college students via self-report. J Pers Assess. 2007;88:205-19.

18 Fite PJ, Raine A, Stouthamer-Loeber M, Loeber R, Pardini DA. Reactive and proactive aggression in adolescent males: examining differential outcomes 10 years later in early adulthood. Crim Justice Behav. 2009;37:141-57.

19 Seara-Cardoso A, Neumann C, Roiser J, McCrory E, Viding E. Investigating associations between empathy, morality, and psychopathic personality traits in the general population. Pers Individ Dif. 2012;52:67-71.

20 Carre JM, Hyde LW, Neumann CS, Viding E, Hariri AR. The neural signatures of distinct psychopathic traits. Soc Neurosci. 2013;8:122-35.
21 Seara-Cardoso A, Sebastian CL, Viding E, Roiser JP. Affective resonance in response to others' emotional faces varies with affective ratings and psychopathic traits in amygdala and anterior insula. Soc Neurosci. 2016;11:140-52.

22 Pardini DA, Raine A, Erickson K, Loeber R. Lower amygdala volume in men is associated with childhood aggression, early psychopathic traits, and future violence. Biol Psychiatry. 2014;75:73-80.

23 León-Mayer E. La psicopatía en prisioneros chilenos: prevalencia y métodos de evaluación [dissertation]. La Plata: Universidad Nacional de La Plata; 2012.

24 Council for International Organizations of Medical Sciences (CIMS). International ethical guidelines for epidemiological studies [Internet]. 2009 [cited 2018 Apr 25]. cioms.ch/wp-content/uploads/2017/01/Inter national_Ethical_Guidelines_LR.pdf

25 Hare RD, Neuman CS. Psychopathy as a clinical and empirical construct. Annu Rev Clin Psychol. 2008;(4): 217-46.

26 Neumann CS, Hare RD, Newman JP. The super-ordinate nature of the psychopathy checklist-revised. J Pers Disord. 2007;21:102-17.

27 Maldonado Zigarán FA. Adaptación del cuestionario autoreportado de psicopatía-III (SRP-III) [thesis]. Salta: Universidad Católica de Salta; 2017. 